\title{
AS METODOLOGIAS ATIVAS E O SEU IMPACTO NO ESPAÇO ENSINO APRENDIZAGEM ATRAVÉS DAS MÍDIAS
}

\section{ACTIVE METHODOLOGIES AND THEIR IMPACT ON THE TEACHING LEARNING SPACE THROUGH THE MEDIA}

\author{
Maria Isabel da Luz Catallani ${ }^{1}$ \\ Thayna Fernanda da Silveira ${ }^{2}$ \\ Sileno Marcos Araújo Ortin ${ }^{3}$ \\ Tiago Moreno Lopes Roberto ${ }^{4}$
}

RESUMO: O objetivo deste artigo é demonstrar a partir de pesquisas bibliográficas aspectos relevantes de como utilizar os recursos disponíveis na prática sobre as metodologias ativas de aprendizagem sob o olhar docente em relação à postura dos profissionais da educação mediante as novas tecnologias digitais. Entende-se que não basta somente conhecer as tecnologias, é preciso também aplicá-las de forma instrutiva e inclusiva nas propostas pedagógicas. A internet, por exemplo, está mudando o mundo. Com ela é possível realizar diversas atividades. O estudo, as pesquisas, as atualizações com os descobrimentos científicos e a transmissão de notícias são algumas das atividades que se pode fazer por meio da rede internacional de computadores. Justifica-se que os avanços tecnológicos e o acesso à informação são muito rápidos e é nessa sociedade do conhecimento/aprendizagem/informação que as crianças estão inseridas e recebem diariamente destas tecnologias de uma quantidade imensurável de informações, as quais precisam ser processadas e filtradas. A metodologia utilizada é a pesquisa exploratória, alicerçada por uma pesquisa bibliográfica baseada em periódicos científicos e livros que versam sobre o assunto objeto de pesquisa. Como toda sociedade está amparada pelas Tecnologias de Informação, gradativamente elas estão ganhando espaço nas escolas e a perspectiva é que fiquem e colaborem para a construção de uma educação com ação integradora e colaborativa, propiciando uma grande desenvoltura no processo de ensino aprendizagem.

Palavras-chave: Aprendizagem. Metodologias ativas. Tecnologia.

ABSTRACT: The aim of this article is to demonstrate, from bibliographic research, relevant aspects of how to use the resources available in practice on active learning methodologies under the teaching eye in relation to the attitude of education professionals

\footnotetext{
${ }^{\mathrm{I}}$ Licenciada em Pedagoga pela Faculdade Futura.

${ }^{2}$ Licenciada em Pedagoga pela Faculdade Futura.

${ }^{3}$ Graduado em Administração (UNIFEV), Especialista em Marketing, Recursos Humanos e Gerência (UNIFEV), Especialista em Programa de Implementação e Gestão em Educação à Distância (UFF), Coordenador de curso de Administração, Mestre em Ciências Ambientais (UNIVERSIDADE BRASIL).

${ }^{4}$ Graduado em Psicologia (UNIFEV), Especialista em saúde mental (FUTURA), Mestre em Psicologia e Saúde (FAMERP), Gestor de Políticas Acadêmicas (FUTURA), Professor do curso de Psicologia (UNIRP).tiago.moreno@faculdadefutura.com.br.
} 
through new digital technologies. It is understood that it is not enough just to know the technologies, it is also necessary to apply them in an instructive and inclusive way in the pedagogical proposals. The internet, for example, is changing the world. It is possible to carry out various activities. The study, research, updates with scientific discoveries and the transmission of news are some of the activities that can be done through the international computer network. It is justified that technological advances and access to information are very fast and it is in this knowledge / learning / information society that children are inserted and receive daily from these technologies an immeasurable amount of information, which needs to be processed and filtered. The methodology used is exploratory research, based on a bibliographical research based on scientific journals and books that deal with the subject object of research. As every society is supported by Information Technologies, they are gradually gaining space in schools and the perspective is that they stay and collaborate for the construction of an education with an integrative and collaborative action, providing a great resource in the teaching-learning process.

Keyword: Learning. Active methodologies. Technology.

\section{INTRODUÇÃO}

Sabe-se que as atuais demandas sociais requerem cidadãos capazes de exercer plenamente a sua cidadania. Isso implica saber analisar criticamente as realidades sociais e

organizar a ação para intervir nessa realidade. Ou seja, a sociedade atual precisa de cidadãos atuantes, que não se limitem a observar a realidade, mas que nela saibam agir, examinar os fatos, articular acontecimentos, prever suas possíveis consequências para a qualidade de vida das pessoas, da cidade, do país, do planeta.

Em decorrência das pressões de diferentes setores da sociedade, percebe-se que as políticas educacionais apresentam sensíveis mudanças, legitimadas em vários documentos oficiais como a Constituição de 1988, a Lei de Diretrizes da Educação nacional (Lei n ${ }^{\circ}$ 9394/96) as Diretrizes Curriculares para a Formação de Professores da Educação Básica, em nível superior, e as Diretrizes Nacionais para a Educação Especial na Educação Básica.

Neste contexto, verifica-se que discutir as questões educacionais no atual cenário brasileiro é uma tarefa complexa, mas necessária, tendo em vista os inúmeros problemas e dificuldades enfrentados com a escolarização, de modo especial com educandos que apresentam dificuldades de aprendizagem e em relação à afetividade constituem-se numa grande preocupação que muito aflige os educadores, os pais, as instituições escolares e os pesquisadores, assim cabe analisar como ocorre a escolarização destes educandos e quais os 
recursos, ou seja, metodologias utilizadas pelos educadores para o ensino de seus educandos.

Portanto, como poderia criar por meio do ensino uma geração capaz de lidar com este panorama desafiador, imerso em diferentes tecnologias que por si só são mais encantadores que uma sala de aula? É preciso refletir nas diversas formas de ensinar e motivar os educandos sem que se perca o objetivo do ensino.

Os avanços tecnológicos e o acesso à informação são muito rápidos. Os jovens de hoje estão cada vez mais atualizados, informados e interessados nos avanços das tecnologias. A escola não pode ficar à margem dessa realidade, repetindo modelos tradicionais de transmissão de conhecimento.

É necessário que o professor seja o mediador no processo de construção de conhecimento, instigando a pesquisa e a troca de ideias e, nesse contexto, o computador, o celular é uma excelente ferramenta que pode tornar o processo educacional mais dinâmico e eficaz, possibilitando ao aluno traçar seu próprio caminho de aprendizagem.

As instituições escolares compõem de componentes essenciais à metodologias ativas digital uma vez que vários protagonistas como os professores, alunos e até os membros da comunidade atuam em conjunto para o processo de construção de conhecimento.

De nada progride o ingresso às tecnologias se não houver acesso à educação. Isto porque o educando com acesso às novas técnicas de ensino deixa de ter um mero papel "inativo" de consumidor de informações, bens e serviços, e então passa ainda a atuar como um elaborador de conhecimentos, bens e serviços.

O objetivo do artigo é comprovar a partir de pesquisas, aspectos relevantes sobre as metodologias ativas de aprendizagem sob o olhar docente, expor referências com relação à substituição do método tradicional de ensino pelas metodologias ativas e apresentar trabalhos relacionados ao tema. Como objetivos específicos, conhecer as características e aplicações dos novos métodos de aprendizagem; entender a importância das metodologias ativas estabelecendo uma possível relação com as tecnologias digitais; conhecer as principais metodologias ativas existentes enfatizando suas características e especificidades; transformar o papel do professor como facilitador efetivo e mediador do conhecimento. 
A metodologia utilizada é a pesquisa exploratória, alicerçada por uma pesquisa bibliográfica baseada em periódicos científicos e livros que versam sobre o assunto objeto de pesquisa. Como toda sociedade está amparada pelas Tecnologias de Informação, gradativamente elas estão ganhando espaço nas escolas e a perspectiva é que fiquem e colaborem para a construção de uma educação com ação integradora e colaborativa, propiciando uma grande desenvoltura no processo de ensino aprendizagem.

Os principais autores pesquisados foram Berbel, (20II); Filatro; Cavalcanti (2018); Freire (1996); Souza in (2006); entre Outros.

\section{DESENVOLVIMENTO}

Em nossa convivência, quando alguém mais experiente nos fala, e aprendemos, descobrimos a partir de um envolvimento mais direto, por questionamento e experimentação, isto é, a partir de perguntas, pesquisas, atividades, projetos. As metodologias que se destacam no ensino são as dedutivas, onde o professor transmite primeiro a teoria e depois o educando deve aplicá-la a situações mais específicas.

[...] não apenas aprendemos desde que nascemos a partir de circunstâncias concretas, que pouco a pouco conseguimos desenvolver e generalizar, encaixando assim o processo indutivo, e aprendemos, além disso a partir de ideias ou teorias para testá-las depois na prática, classificando o processo dedutivo, para nos adaptarmos à realidade, mas, sobretudo, para transformar, para nela intervir, recriando-a (FREIRE, 1996 p. 28).

O conjunto de metodologias, técnicas e artifícios para orientar a instrução de princípios aplicáveis a todas as disciplinas, para aprender a mesma é realizada de forma mais competente. O estudo do ensino é necessário para tornar a educação mais hábil, mais adaptada à natureza e as possibilidades do educando e da sociedade. As preocupações dos educadores sobre os estudos de ensino referidos não são recentes.

"A aprendizagem é mais significativa quando motivamos os alunos intimamente, quando eles acham sentido nas atividades que propomos, [...] quando há diálogo sobre as atividades e a forma de realizá-las” (MORAN, 2018 p. 36). 
Para que a aprendizagem significativa ocorra o professor deve ir além da simples transmissão de conteúdo, ele deve traçar estratégias e situações que motivem o aluno na aquisição de conhecimentos relevantes as suas necessidades, com propostas inovadoras que faça com que o aluno seja protagonista de sua aprendizagem.

Acreditava-se que para ser um bom professor, deveria se conhecer bem, o suficiente, a disciplina para ensinar bem. Não é só importar com o que é valioso, é necessário considerar também o aluno e seu desenvolvimento físico, emocional, cultural e social. É claro que, para ensinar bem, corresponde a considerar técnicas de ensino adequadas ao nível de desenvolvimento, interesses, possibilidades e peculiaridades do aluno (GUILLOT, 2008).

Entender tais conceitos é o meio pelo qual se procura adquirir apoio, para basear o trabalho docente, no sentido de encontrar modos competentes que garantam uma educação de qualidade aos seus alunos.

Sendo assim, toda aprendizagem é ativa em algum grau, pois exige do educando e do professor metodologias diferenciadas tanto internas como externa, que motiva, seleciona, interpreta, compara, avalia e aplica. "A curiosidade, o que é diferente e se destaca no entorno, desperta a emoção. E, com a emoção, se abrem as janelas da atenção, foco necessário para a construção do conhecimento" (MORA, 2013, p. 66).

Essa aprendizagem, para que se torne mais intensa demanda de espaços de prática frequentes, ou seja, o aprender fazendo e de ambientes que favoreça oportunidades. Por isso, é imprescindível o estímulo multissensorial, onde o professor adquire através dos conhecimentos prévios dos educandos para seguir com novos conhecimentos.

Muitos educadores que atuam nas escolas não se dão conta da importante extensão que tem o seu papel na vida dos educandos. Pois, não há como ocorrer na escola uma educação adequada às necessidades dos educandos, sem contar com o comprometimento funcional do educador, no processo educativo.

Porém, ao achegar-se na figura de alguns educadores, observa-se que muitos, fundamentados no senso comum, acreditam que ser educador é apropriar-se de um conteúdo e apresentá-lo aos educandos em sala de aula (PIMENTA, 2005). 
Transformar essa realidade é preciso, para que uma nova afinidade entre educadores e educandos comece a existir dentro das escolas. No entanto, é necessário entender que a tarefa docente tem um papel social e político insubstituível, e que no momento atual, embora muitos fatores não colaborem para essa compreensão, o educador necessita admitir uma postura crítica em relação ao seu desempenho readquirindo a essência do ser professor.

E para o educador compreender a real definição de seu trabalho, é preciso que saiba um pouco mais sobre sua identidade e a história de sua profissão.

Teríamos que conseguir que os outros acreditem no que somos. Um processo social complicado, lento, de desencontros entre o que somos para nós e o que somos para fora [...] Somos a imagem social que foi construída sobre o ofício de mestre, sobre as formas diversas de exercer este ofício. Sabemos pouco sobre a nossa história (ARROYO, 2000 p. 29).

Fazendo uma relação com esse ponto de vista, não se pode consentir em destacar e valorizar os fenômenos histórico-sociais presentes na atividade profissional do educador.

Considerando a manifestação de se trabalhar a identidade do educador, observa-se uma vasta bibliografia sobre a profissão docente, a qual tem proporcionado muitas ideias e questionamentos, especialmente sobre a formação dos educadores, e, mais designadamente, sobre a formação reflexiva dos educadores (SAVIANI, 2007).

Segundo Libâneo (2005), é essencial se informar que tipo de reflexão o educador necessita para transformar sua prática, pois para ele,

A reflexão sobre a prática não resolve tudo, a experiência refletida não resolve tudo. São necessárias estratégias, procedimentos, modos de fazer, além de uma sólida cultura geral, que ajudam a melhor realizar o trabalho e melhorar a capacidade reflexiva sobre o que e como mudar (LIBÂNEO, 2005 p. 76).

Assim sendo, ao refletir sobre a formação de educadores percebemos que o educador nunca está acabado e que os estudos teóricos e as pesquisas são essenciais, no sentido de que é por mediação desses instrumentos que os educadores terão condições de considerar 
criticamente os contextos históricos, sociais, culturais e organizacionais, nos quais sobrevêm as atividades docentes, podendo assim intervir nessa realidade e transformá-la.

\section{A RELAÇÃO PROFESSOR E ALUNO NO PROCESSO DE ENSINO E APRENDIZAGEM}

O relacionamento humano é peça essencial na realização comportamental e profissional. Assim, a análise dos relacionamentos entre professor/aluno abrange interesses e intenções, sendo este intercâmbio o expoente das implicações, pois a educação é uma das fontes mais importantes do desenvolvimento comportamental e associação de valores nos componentes da espécie humana (GADOTTI, 2000).

Neste sentido, a interação estabelecida caracteriza-se pela seleção de conteúdos, organização, sistematização didática para assim promover o aprendizado dos educandos e apresentação onde o educador comprovará seus conteúdos.

No entanto este modelo deve ser quebrado, é necessário não limitar este estudo em

relação comportamento do educador com resultados do educando; devendo introduzir os

processos construtivos como intermediários para exceder as limitações do paradigma processo-produto.

O professor para pôr em prática o diálogo, não deve colocar-se na posição de retentor do saber, deve antes, colocar-se na posição de quem não sabe tudo, reconhecendo que mesmo um analfabeto é portador do conhecimento mais importante: o da vida (GADOTTI, 200o, p. 2).

Desta maneira, o aprender se torna mais importante quando o educando se sente competente pelas ações e metodologias de motivação em sala de aula. $O$ prazer pelo aprender não é uma atividade que aparece prontamente nos educandos, pois, não é uma tarefa que exercem com contentamento, sendo em alguns casos enfrentada como obrigação. Para que isto possa ser melhor cultivado, o educador deve abrir os olhos para a curiosidade dos educandos, seguindo suas ações no desenvolver das atividades.

O educador não deve preocupar-se exclusivamente com o conhecimento por meio da absorção de informações, mas também pelo processo de construção da cidadania do 
educando. Embora, para que isto aconteça, é indispensável à conscientização do educador de que seu papel é de facilitador de aprendizagem, aberto às novas experiências, buscando compreender, numa relação empática, também os sentimentos e os problemas de seus educandos e tentar levá-los à autorrealização (FAXINA, 2005).

De modo concreto, não podemos pensar que a construção do conhecimento é entendida como subjetivo. O conhecimento é produto da atividade e do conhecimento humano caracterizado social e culturalmente. O papel do educador incide em atuar como mediador entre os conteúdos da aprendizagem e a atividade construtiva para absorção.

O trabalho do educador em sala de aula, seu relacionamento com os educandos é expresso pela afinidade que ele tem com a sociedade e com sua cultura.

É o modo de agir do professor em sala de aula, mais do que suas características de personalidade que colabora para uma adequada aprendizagem dos alunos; fundamenta-se numa determinada concepção do papel do professor, que por sua vez reflete valores e padrões da sociedade (ABREU; MASETTO i99o, p. i15).

Desse modo, o professor deve ser consciente de que seu papel é o de facilitador de aprendizagem, ou seja, agir como intermediário entre os conteúdos da aprendizagem e a atividade construtiva para assimilação ativa do conhecimento.

O bom educador é o que impetra, enquanto fala trazer o educando até a intimidade do movimento do seu pensamento.

"Sua aula é assim um desafio e não uma cantiga de ninar. Seus alunos cansam, não dormem. Cansam porque acompanham as idas e vindas de seu pensamento, surpreendem suas pausas, suas dúvidas, suas incertezas" (FREIRE 1996, p. 96).

A relação entre educador e educando depende, necessariamente, do clima estabelecido pelo educador, da relação empática com seus educandos, de sua capacidade de ouvir, refletir e discutir o nível de compreensão dos educandos e da criação das pontes entre o seu conhecimento e o deles.

Faxina (2005) sugere que o educador da era industrial com raras observações, deve procurar educar para as transformações, para a autonomia, para a liberdade plausível numa 
abordagem global, trabalhando o lado positivo dos educandos e para a formação de um cidadão consciente de seus deveres e de suas responsabilidades sociais

\section{BUSCANDO A MUDANÇA E A TRANSFORMAÇÃO}

Debater a questão da modificação e da transformação implica em ver o primeiro termo como uma proposta a ser destacada e, como toda proposta, está permeada por metas, objetivos e passos que induzem a um fim específico, que aqui, poderia ser colocado como o processo de graduação propriamente dito do educador (PIMENTA, 2005).

Para o segundo termo, seria apropriado refletir os resultados da ação do educador. Em linhas gerais, esse julgamento expede a noção de que transformar é preciso, no entanto, deve ser um processo adaptado pela transformação, que no caso do ensino, traduz-se pelo investimento de um processo mais interiorizado: a aprendizagem.

O ensino é pensado a partir de situações-problema, orientado por conceitos norteadores, objetivando a aquisição de competências e habilidades que conectam o ser humano ao seu ambiente socioeconômico-cultural (SOUZA; AMARAL; SCHIMIGUEL, 2006)

De acordo com os autores, o aprendizado é a realidade do educando e muito mais significativo, uma vez que desperta a curiosidade em buscar novos conhecimentos e adquirir novas perspectivas. Ainda sugerem a apresentação de situações-problema antes que os conteúdos sejam apresentados, tornando-se assim a inversão do processo de ensinoaprendizagem.

São apresentadas metodologias como vídeos gravados pelos educadores aos educandos antes de apresentarem a aula, em seguida discutem o tema, compartilham informações e ideias para a solução do problema como base do estudo futuro.

Este método faz com que o educando interaja de maneira mais ativa, aproxima o conteúdo da sua realidade, permitindo a resolução de dúvidas junto ao educador mediador (TEIXEIRA, 2009).

Nesse sentido, algumas orientações são pertinentes ao tema: 
É preciso insistir que tudo quanto fazemos em aula, por menor que seja, incide em maior ou menor grau na formação de nossos alunos. A maneira de organizar a aula, o tipo de incentivos, as expectativas que depositamos, os materiais que utilizamos, cada uma destas decisões veicula determinadas experiências educativas, e é possível que nem sempre estejam em consonância com o pensamento que temos a respeito do sentido e do papel que hoje em dia tem a educação (ZABALA, 1998 p. 29).

Esclarecer a necessidade de mudança e de transformação porque passa o ensino atualizado, provoca em apreender que as instituições escolares vêm sendo impelidas a repensar seu papel perante das transformações que diferenciam o acelerado processo de consistência e reestruturação capitalista mundial.

Assim, essas transformações, [...] “decorrem da conjugação de um conjunto de acontecimentos e processos que acabam por caracterizar novas realidades sociais, políticas, econômicas, culturais, geográficas" (LIBÂNEO, 2005, p. 45).

Para o autor, dentre os aspectos mais manifestos desse elemento destacam-se os avanços tecnológicos, a globalização da sociedade, a propagação da informação, a gravidade da exclusão social, entre outros fatores. Perante tamanha complicação, pergunta-se quem segurará tal conhecimento a ponto de transpor o cidadão que irá desempenhar tais habilidades. Como encontrar um profissional que retribua aos perfis socialmente constituídos pelas exigências sociais?

Idealizando a escola, enquanto um espaço correspondente para formar o cidadão dos apoios de conhecimento para uma vida em equilíbrio sobre a sociedade, persiste em repensar a atuação de um professor preparado teórica e praticamente, de modo a ministrar um ensino para a transformação. No entanto, salienta-se, que a transformação social não é incumbência somente da escola, entretanto, ela é um dos caminhos mais abordados para isso.

$\mathrm{Na}$ visão de Feracine (1998) a educação e a escola só podem ser verdadeiramente transformadoras se permanecerem maturando as alternativas, de modo a exceder as soluções da radicalidade extremista, cujo negativismo completará por recriar os problemas que aspiravam descarregar. 
É nessa totalidade, que a formação permanecida encontra o seu espaço nas necessidades pedagógicas, visto que, conforme afirma Libâneo (2005),

[...] a formação continuada pode possibilitar a reflexividade e a mudança nas práticas docentes, ajudando os professores a tomarem consciência das suas dificuldades, compreendendo-as e elaborando formas de enfrentá-las. De fato, não basta saber sobre as dificuldades da profissão, é preciso refletir sobre elas e buscar soluções, de preferência, mediante ações coletivas [...] (LIBÂNEO, 2005 p. 32).

Com base no publicado, torna-se crucial, repensar a atuação do professor além do exercício da sala de aula, além das complicações de preenchimento de fichas, entre outros tantos afins. Contudo, é preciso, seguramente, que a formação continuada seja vista como uma fase procedimental e atitudinal da prática docente, dirigindo à melhoria do ensino e o rompimento de uma visão de mundo estancada. Porque, ser educador, é muito mais que ser um profissional do ensino, mas um cientista do ato político.

\section{O SABER-FAZER COMO INSTRUMENTO DE INTERVENÇÃO PEDAGÓGICA}

O ponto de partida e o ponto de chegada da intervenção pedagógica é a leitura do verdadeiro, ou seja, da totalidade, dos sujeitos e das inter-relações que se dão entre os atores sociais. $O$ educador não exerce o saber-fazer unicamente em sua formação inicial e nem ainda este saber-fazer se conclui em um ano ou dois de formação continuada, antes é processo estável das leituras possíveis da realidade; portanto, para cada realidade "lida", uma intervenção lógica e sólida com suas solicitações; pois prefere as mesmas respostas para realidades distintas, para definição e redefinição de mundo pelos indivíduos é amortizar a educação a uma linha de produção, onde a seriação, os tempos e os movimentos são cultiváveis em algum caso (FREIRE, 1996).

O saber-fazer, contudo, parte de uma concepção humana da realidade, onde figura como o mais importante à possibilidade de se trabalhar a intervenção pedagógica pela necessidade do grupo, pela identificação das revelações que impactam mais e de forma significativa aos alunos, não basicamente apenas o causa encanto, mas também o que solicita a concentração, o que requer o desafio, o que solicita a significação da trajetória escolar e desta numa contextualização social, da qual a escola não está a par. 
Segundo Martinic (2015), o saber-fazer, não se restringe ao conhecimento de várias técnicas e metodologias de ensino, mas com o que fazer para a promoção da qualidade da intervenção, derivando numa aprendizagem significativa, ponderando o desenvolvimento das habilidades e aptidões discentes, sem negar-lhes o conteúdo de acordo com a história causado e cobrado em vários interesses da vida social.

Lima (2007) relata que o educador consciente desta dimensão terá a sua ação pedagógica norteada pela sensibilização da leitura de mundo, integrando-a leitura do mundo sistematizado do conhecimento; desta forma, não nega a validade das metodologias e técnicas de ensino, mas trata-as como uma base possível dentro de uma leitura máxima.

Suporte este que poderá ser ajustado de acordo com as respostas ou direções que a realidade social requer, resultando diferentes intervenções para caracterizadas realidades, pois a leitura do mundo antecipa a leitura da intervenção pedagógica apreciando a escola e sua totalidade contextual como objetos que não se quebram e não podem ser ponderados de maneira fechada.

É necessário implantar no ensino novas propostas pedagógicas com o objetivo de desenvolver as competências e habilidades de formação no nível de ensino em que os alunos estão inseridos. As metodologias ativas aparecem com o objetivo de estimular a construção de conhecimentos fundamentada em problemas para possíveis soluções.

As metodologias ativas de aprendizagem adquirem papel importante nas atividades de ensino, uma vez que proporcionam ao aluno oportunidades significativas de intervenção na realidade concreta, seja individualmente, com seus professores ou com os demais alunos (SANTOS, 2009 p. 27).

Esta leitura é um dos pilares da educação formal na atualidade que evidencia os "olhares sensíveis" do educador em relação ao fenômeno educacional e que se estendem em intervenções exatas e lógicas em direção à educação de qualidade que se ambiciona.

Rodrigues (2016, p. 25) "baseiam-se em formas de desenvolver o processo de aprender, utilizando experiências reais ou simuladas, visando às condições de solucionar, com sucesso, desafios das atividades essenciais da prática social, em diferentes contextos”.

A sala de aula é o espaço no quais educadores e educandos se encontram e interagem em torno do conhecimento. Essa interação, que constitui parte decorrente da forma como professor vê o processo de ensino-aprendizagem. 
Para Paiva et all (2016) as metodologias ativas constituem-se em desafios e benefícios para o processo de ensino e aprendizagem e há diferentes modelos e alternativas para sua operacionalização.

A ideia que se tinha no passado, de alunos como pessoas relativamente fáceis de serem moldadas e dirigidas a partir do exterior, não existem mais. Foi suprida e entendida como, oposto, eles elegeram determinados aspectos do meio físico e social, processaram, conferindo-lhes sentidos.

De acordo com Berbel (2011),

(...) as Metodologias Ativas baseiam-se em formas de desenvolver o pro - cesso de aprender, utilizando experiências reais ou simuladas, visando às condições de solucionar, com sucesso, desafios advindos das atividades essenciais da prática social, em diferentes contextos (BERBEL, 2011 p. 29).

A aprendizagem era apresentada como produto quase que específico do comportamento do educador e da metodologia de ensino seguida, atualmente as contribuições através de metodologias ativas: seus conhecimentos, capacidades e habilidades prévias, sua percepção da escola e do educador, suas perspectivas e atitudes diante do ensino. Sem pressa, os educandos vão adequando dos ensinamentos da escola, a luz do que já conhecem. Nessa medida estabelecem seus conhecimentos.

\section{APRENDIZAGEM ATIVA E METODOLOGIAS ATIVAS}

A educação acontece por um momento de mudança que busca inovação, qualidade no ensino, no progresso de novas habilidades e novas metodologias, com o objetivo em preparar novos profissionais em resposta a um mercado em integral ampliação, cada vez mais competidor e com novas tecnologias envolvidas. Neste movimento, as instituições de ensino, através de suas estruturas e corpo docente, devem estar em constante atualização para dar feed back significativos e satisfatórios em relação aos seus sistemas de ensino, preparando uma nova geração de profissionais em suas respectivas áreas de conhecimento.

As metodologias ativas veio segundo Oliveira e Pontes (2013) como resposta desafiadora na educação, que apresenta como um método amplo e tem como fundamental 
característica a inclusão do educando como administrador principal responsável pela sua aprendizagem.

De acordo com Moran (2018) o objetivo desta metodologia de ensino é estimular os educandos para que aprendam de forma independente e participativa, a partir de problemas e situações reais. A proposta é que o mesmo permaneça no centro do processo de aprendizagem, como mostra a figura (I) participando efetivamente e sendo responsável pela construção de conhecimento.

Figura 1: Metodologias Ativas

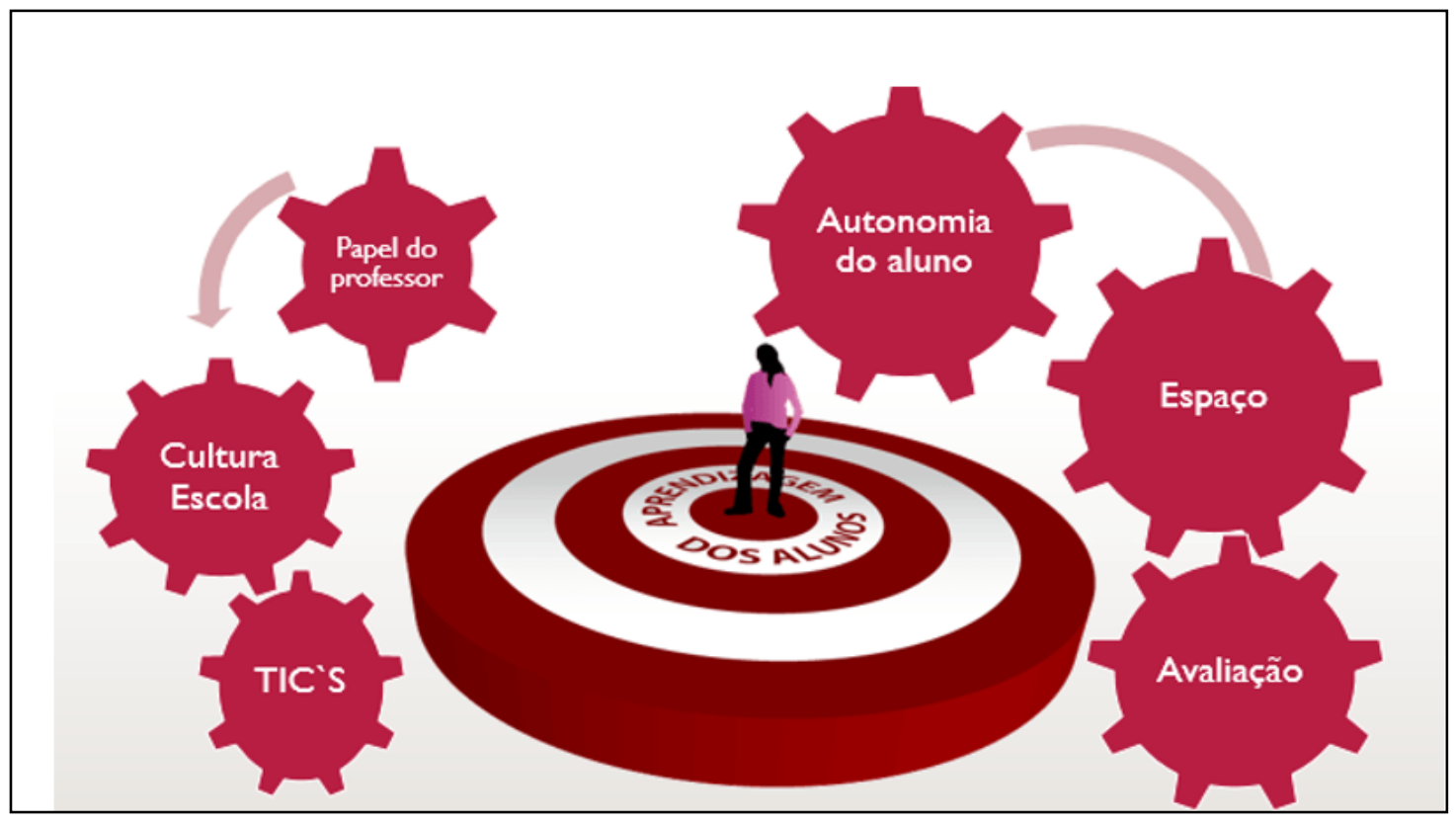

Fonte: MORAN (2018)

De acordo com Anastasiou e Alves (2004), Berbel (2011) e Pereira (2012) justificam a utilização de práticas pedagógicas inovadoras para aperfeiçoar os métodos de ensino e de aprendizagem. Os autores defendem, unicamente a ação intelectual do docente e a reprodução do livro didático deixam de ser pesquisas específicas do saber na sala de aula, tornando o educando o ator principal do processo. Deste modo, entram as metodologias ativas de ensino e de aprendizagem, em que o foco da aprendizagem está centralizado no aluno. 
Os impedimentos no aprendizado modificam de aluno para aluno, e estabelecem meios distintos de ensino. Mas isso faz parte de todo essa metodologia de ensino, e novas metodologias acabam nascendo a cada instante em que surgem novos desafios, e nortear cada sujeito de modo tal que consiga edificar novos conhecimentos e aperfeiçoar habilidades na solução dos desafios atribuídos e, como resultado, alcançar os desígnios propostos nas atividades.

De acordo com Pereira (2012),

Concordar a essa prática do professor que esteja valorizando a ação do aluno permite várias possibilidades de organização de ações didáticas e visa, sobretudo, o processo de aprender tendo como referência a inserção progressiva do acadêmico no universo profissional de sua formação, resolvendo problemas e aprofundando sua compreensão (PEREIRA, 2012, p. 6).

Quando se utiliza de práticas dirigidas pelas metodologias ativas de ensino e de aprendizagem, o educador determina ao educando um maior inclusão no processo de ensino e de aprendizagem, pois ele é o principal responsável, tendo a iniciativa tomando decisões e a partir daí debater opinião com os companheiros, posicionar-se perante deles, entre outros.

Berbel (20II) destaca que as metodologias ativas de ensino e de aprendizagem cooperam com a promoção da autonomia dos alunos criando a curiosidade, à medida que lhes é admitido trazer informações novas às aulas, os quais, quando considerados e estudados, fazem o educando sentir-se valorizado.

Diante a problemática, o método de integração de metodologias ativas no processo de ensino precisa considerar as dificuldades apresentadas pelo educando.

O engajamento do aluno em relação a novas aprendizagens, pela compreensão, pela escolha e pelo interesse, é condição essencial para ampliar suas possibilidades de exercitar a liberdade e a autonomia na tomada de decisões em diferentes momentos do processo que vivencia, preparando-se para o exercício profissional futuro (BERBEL, 20II, p. 29). 
O sucesso de uma metodologia se dá a partir do período em que se deposita o educando determinando dificuldades reais e, sendo um desafio, acaba sendo um tanto motivador e logo o envolvimento advém de forma natural.

As informações não são exclusivamente transmitidas, mas são problematizadas, induzindo ao educando a pesquisar, questionar e refletir sobre os conhecimentos da eletrônica e sobre os experimentos práticos. Abordagens que exigem que o aluno estude, pesquise, analise, reflita e tome decisões de forma individual ou coletiva em prol da resolução de um problema, são denominadas metodologias ativas (BERBEL, 20II).

As metodologias ativas dependem muito da atuação humana entre professores, alunos, especialistas, representantes da comunidade, ou seja, propõem um tipo de inovação relacionado a progressos que pode ser adotado dentro do circuito escolar-universitário, sem desorganizar a estrutura clássica das instituições de ensino.

Cabe ao professor o papel de mediador e orientador de todas as etapas e propor situações a serem resolvidas, devendo organizar e direcionar estes trabalhos, fazendo com que os alunos tenham contato com determinados assuntos, utilizando de fato as novas técnicas e metodologias.

\section{APLICANDO AS METODOLOGIAS ATIVAS}

A partir do nível de autonomia que os educandos possuem para aprender é aplicada as metodologias ativas. Freire considera que a autonomia é fator fundamental no processo de aprendizagem, pois equivale à capacidade de uma pessoa agir por si mesma, sem depender de outras pessoas. Freire (1996) explica que a construção da autonomia deve estar centrada na vivência de experiências estimuladoras que advêm da tomada de decisão e da possibilidade de o aluno assumir responsabilidade por sua própria aprendizagem. $\mathrm{O}$ autor considera que a autonomia é o ponto de equilíbrio entre a autoridade do professor e a liberdade do aprendiz. Por isso, a autonomia produz autoconfiança, estimulando os alunos a exercer um papel ativo no processo de aprender.

Sendo assim, o professor que atua na educação básica sabe que as crianças, que são menos autônomas por ainda estarem passando pelos estágios de desenvolvimento físico e psicológico, precisam de maior direcionamento e orientação para desenvolver projetos 
baseados em metodologias ativas que os adultos, estes sim maduros fisiológica e psicologicamente, os quais participam de ações de educação corporativa.

De acordo com Bonwell; Eison (I99I) também é preciso considerar que as metodologias ativas são compostas de dois aspectos fundamentais: ação e reflexão. Isto significa que, nos contextos em que as metodologias ativas são adotadas, o aprendiz é visto como um sujeito ativo, que deve tanto envolver-se de forma intensa em seu processo de aprendizagem quanto refletir sobre aquilo que está fazendo. A articulação entre açãoreflexão estimula que os educandos vivenciem a metacognição, ou seja, a compreensão e o auto monitoramento de sua própria aprendizagem.

$\mathrm{Na}$ verdade, nesse processo as ferramentas tecnológicas podem ser usadas para desenvolver a autonomia dos aprendizes e possibilitar a agilidade e a personalização das experiências de aprendizagem, além da experimentação e comunicação rápida de pessoas separadas por tempo e espaço.

$\mathrm{Na}$ pedagogia, geralmente adotada em ambientes acadêmicos regulamentados como nas escolas as crianças e jovens recebem orientações específicas do professor para desenvolver as atividades propostas. Assim, a pedagogia articula-se com as correntes do cognitivismo e do (sócio) construtivismo por beber dessas fontes para utilizar metodologias ativas em contextos reais. Como exemplo, podemos dizer que o professor que orienta duplas ou grupos de alunos para que respondam questões a partir de dados, elaborem mapas mentais com representações gráficas de relações existentes entre um conjunto de conceitos trabalhados no conteúdo curricular.

O professor ainda pode desenvolver em sala de aula, segundo Filatro; Cavalcanti (2018) atividades como: Aprendizagem baseada em projetos, faz com que os alunos construam seus saberes de forma colaborativa, através da solução de desafios. Tem por objetivo final a entrega de um produto que pode ser um relatório das atividades realizadas, um protótipo da solução concebida ou um plano de ação a ser implementado na comunidade local. Do mesmo modo, o educando deve se esforçar para criar, descobrir e testar as hipóteses a partir de sua própria vivência. $\mathrm{O}$ educador pode abranger tecnologias como vídeos ou fóruns digitais, além de sugerir atividades que abranjam informações concretas, como cartazes e maquetes. A fim de desenvolver nos educandos uma 
representação investigativa e crítica diante das situações propostas. O ponto fundamental é consentir que o educando busque o saber por si mesmo. E não significa que o professor não precise estar presente, isto é, cabe a ele agir como orientador de caminhos, dando feedbacks e mostrando erros e acertos ao longo do processo.

Existem diversos tipos de metodologias ativas como exemplo está evidenciada, Aprendizagem baseada em problemas, Gamificação, Sala de aula Invertida, Ensino Híbrido.

- Aprendizagem baseada em problemas (figura 2), recomenda ao educando a construção de conhecimento por meio de debates e júris, discutindo em grupo um problema. Na prática, o educando estuda um determinado assunto antes da aula. Em seguida, apresenta suas dúvidas e dificuldades para o encontro com o professor e os colegas, discutindo sobre sua interpretação. A metodologia rompe o paradigma de aula tradicional, com disciplinas curriculares distanciadas umas das outras. Portanto, a participação de cada um torna-se ativo, estimulando o trabalho em grupo e a comunicação entre conhecimentos de diferentes campos do currículo escolar. Observa-se um grande aliado essa atividade com a Base Nacional Comum Curricular (BNCC), pois requer a interdisciplinaridade.

Figura 2: Aprendizagem baseada em problemas

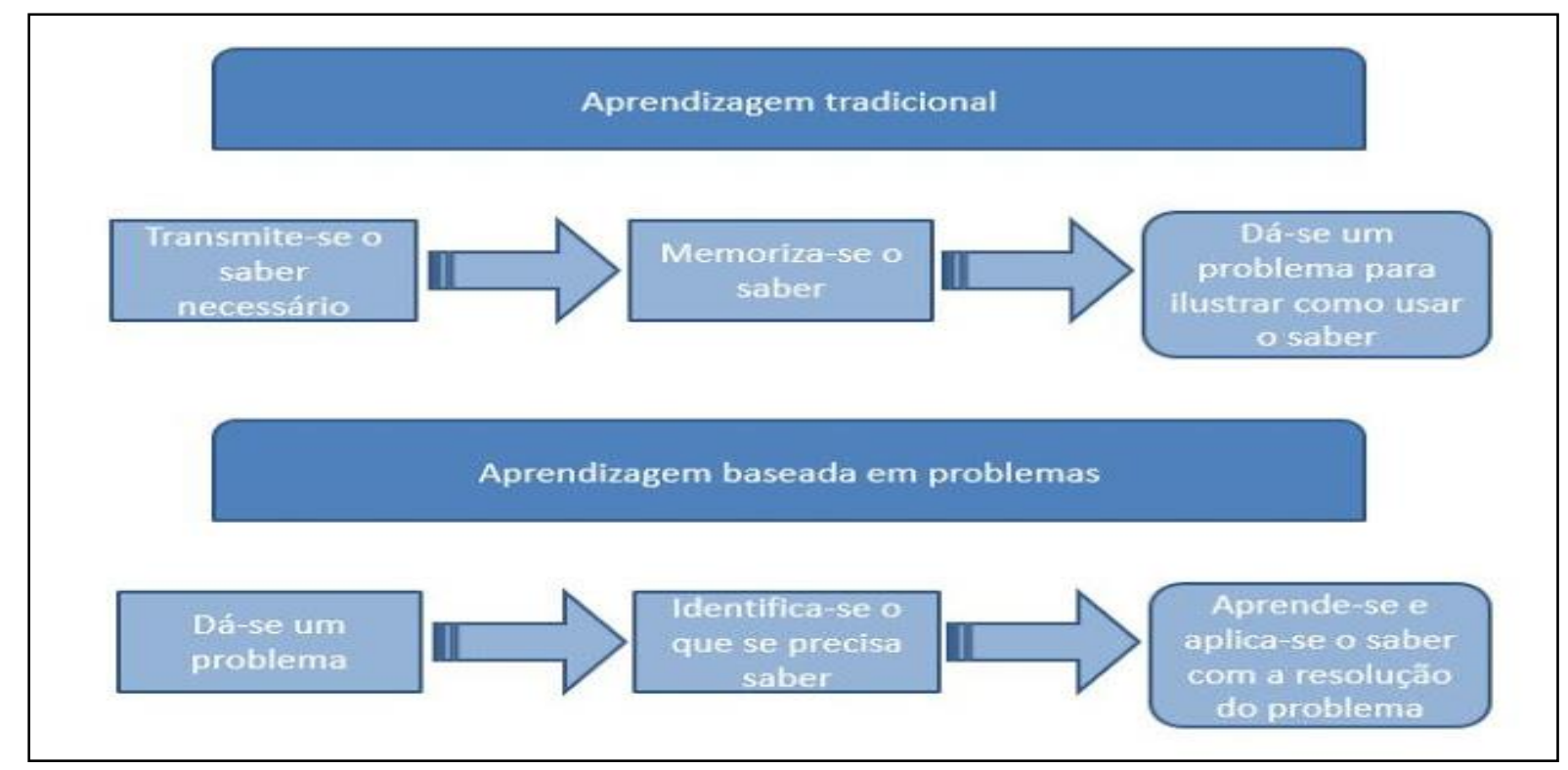

Fonte: RODRIGUES (2016) 
- A gamificação (figura 3), seria outra metodologia ativa, criando situações de sala de aula, ou seja, jogos e desafios. Sua metodologia é especialmente aproveitada para provocar maior engajamento, motivar a ação, causar a aprendizagem ou resolver problemas de modo criativo. Sendo assim, o professor auxilia os educandos a perderem a resistência perante temas complicados. Através de desafios individuais ou em grupo, é possível causar uma maior participação em sala de aula. Compete ao professor desenvolver dinâmicas inteligentes e que chamem a atenção, provocando o aprofundamento didático e não apenas um momento de interação coletiva.

Figura 3: Gamificação

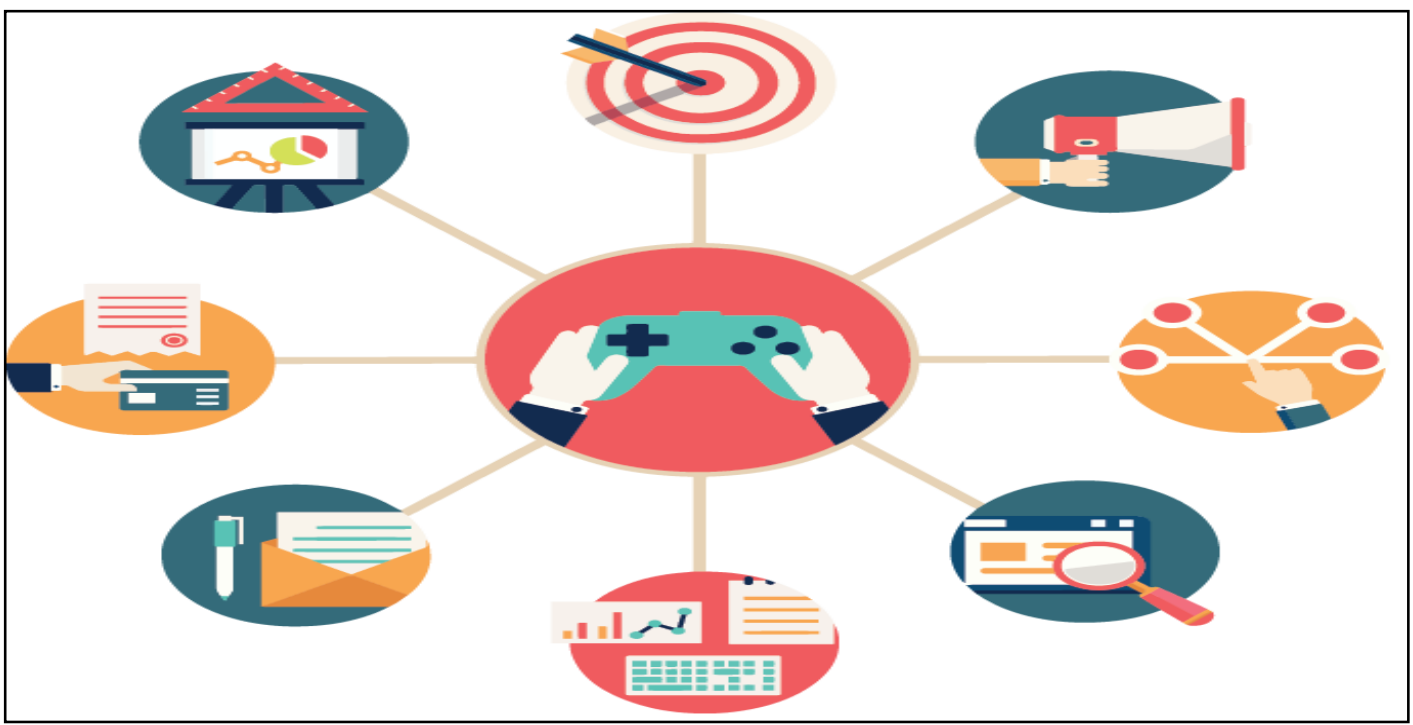

Fonte: https://www.google.com.br/imagem

- A sala de aula invertida (figura 4), conhecida como flipped classroom, é uma metodologia ativa no uso da tecnologia, ou seja, especialmente a internet, pois mistura a experiência digital e de sala de aula, desenvolvendo o aprendizado. Essa metodologia funciona em duas formas: Online: precede a aula em grupo. É onde o educando estuda sozinho, aproveitando materiais da internet com a orientação do educador. Presencial: é onde o educando partilha com o grupo seu entendimento do tema, trocando conhecimentos com o educador e os colegas. Para que esse método da sala de aula invertida funcione, é necessário que os educandos apoiem a proposta, empenhando-se com o desafio. Nessa nova metodologia, o educador é responsável pela qualidade do ensino que irá receber, 
enquanto o educador apresenta um bom planejamento de aula, pois vai conectar de maneira dinâmica e didática aos conteúdos oferecidos para a classe.

Figura 4: Sala de aula Invertida

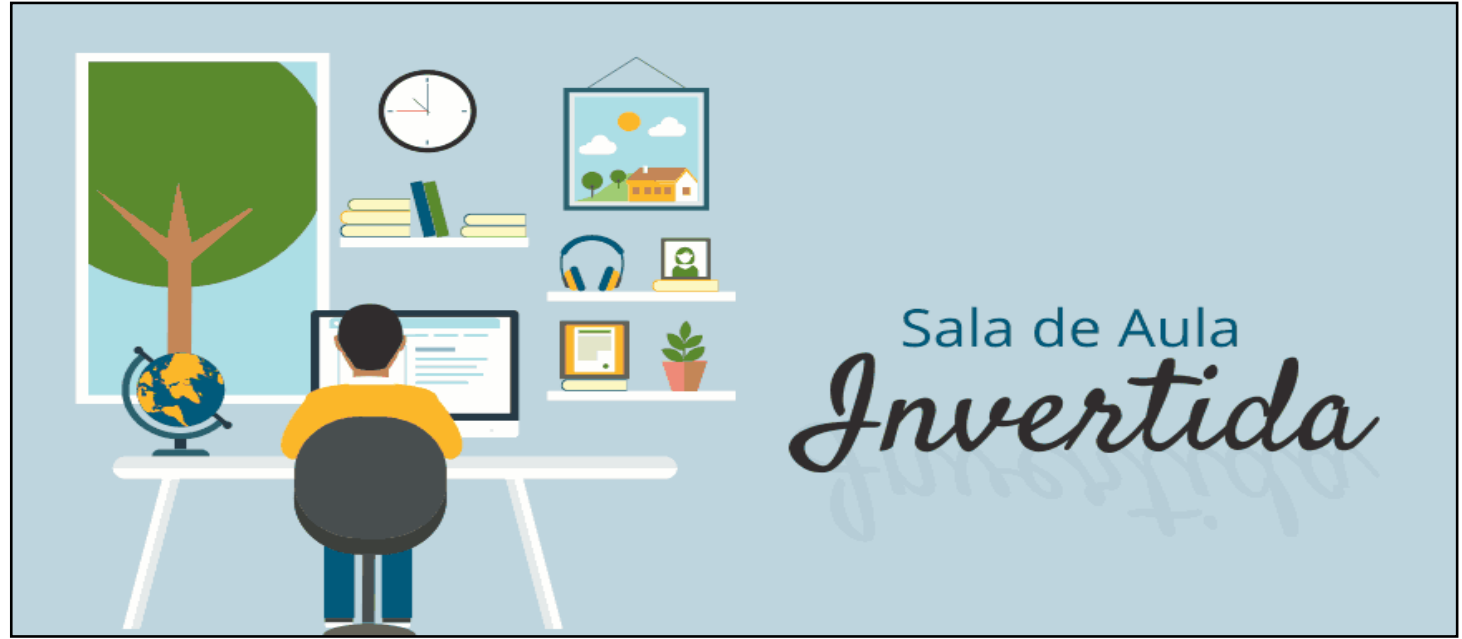

Fonte: https://www.google.com.br/imagem

- Ensino Híbrido (figura 5), além de ser uma metodologia ativa busca unir de maneira equilibrada o ensino a distância e o ensino presencial. Com essa união, os alunos deverão ser muito mais ativos em seu processo de ensino-aprendizagem, já que precisarão de disciplina e muita concentração para aprenderem via EAD. E, além disso, o uso da tecnologia como meio de aprendizagem vai fazer com que os alunos produzam conhecimento de maneira mais autônoma.

Figura 4: Ensino Híbrido

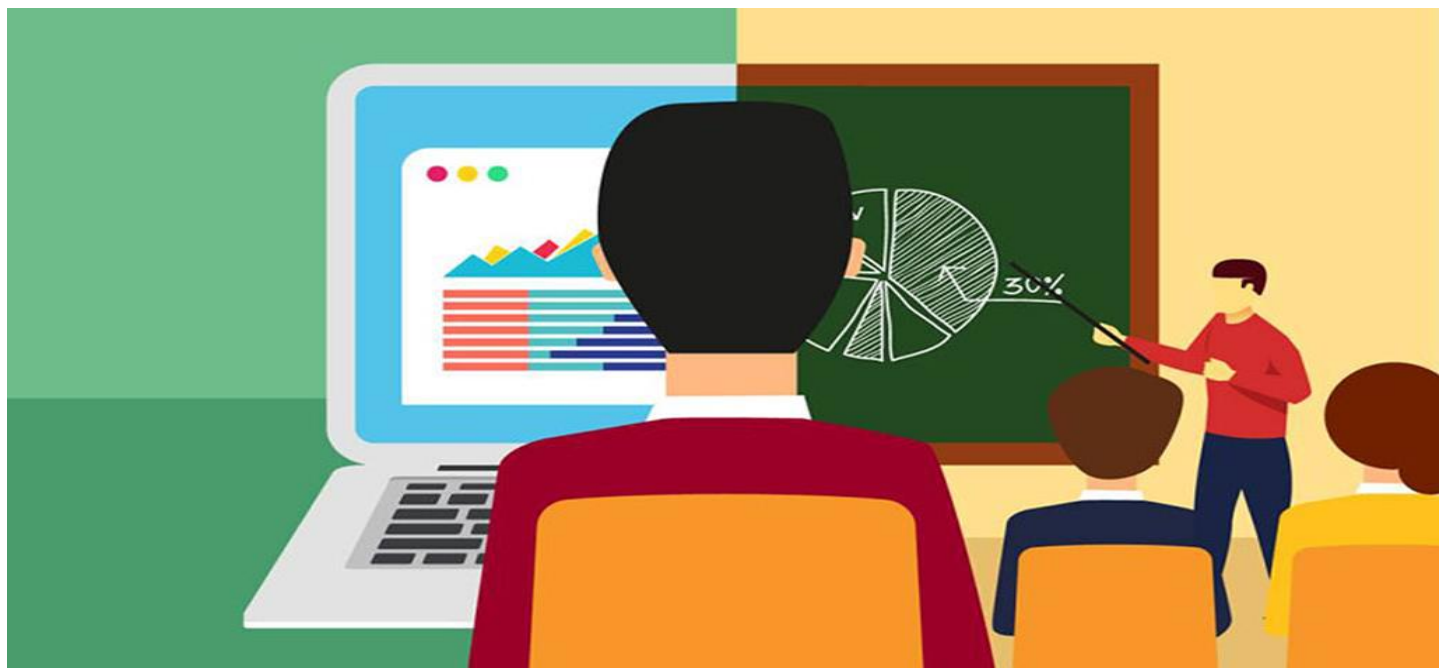

Fonte: https://www.google.com.br/imagem 
A aplicação de metodologias ativas é ampla e pode variar de acordo com o nível de protagonismo assumido pelo aprendiz. Ou seja, dependendo da atividade, estratégia ou tendência proposta, o aprendiz assume diferentes papéis (dos mais simples aos mais complexos).

Buscando conciliar a teoria acadêmica com a prática do dia a dia da sala de aula, foi indicado a criação de um plano de aula que contemplam a implementação dessas metodologias ativas, como atividades em times onde a turma se divide em grupos. Assim, o professor orienta a atividade, que pode ser baseada nos métodos citados anteriormente, e os alunos são estimulados a chegar a uma solução colaborativa para o que lhes foi proposto, de modo que os educandos aprendam a divergir ideias e chegar a uma conclusão do grupo. 


\begin{tabular}{|c|c|}
\hline \multicolumn{2}{|c|}{ PÚBLICO: $5^{\circ}$ ANO - ENSINO FUNDAMENTAL I } \\
\hline \multicolumn{2}{|l|}{ DURAÇÃO: I HORA } \\
\hline $\begin{array}{l}\text { UNIDADE } \\
\text { TEMÁTICA: }\end{array}$ & GÊNEROS TEXTUAIS \\
\hline $\begin{array}{l}\text { HABILIDADE(S) - } \\
\text { BNCC }\end{array}$ & $\begin{array}{l}\text { EFIsLPor- identificar a função social de textos que circulam em campos da vida social dos quais participa } \\
\text { cotidianamente } \\
\text { EFisLPo2- Estabelecer expectativas em relação ao texto que vai ler (pressuposições antecipadoras dos sentidos, da } \\
\text { forma e da função social do texto) } \\
\text { EFIsLPo3- Localizar informações explícitas em textos. }\end{array}$ \\
\hline JUSTIFICATIVA & $\begin{array}{l}\text { O SARESP é uma avaliação censitária, uma vez que se trata de um sistema que avalia o ensino em sua totalidade: } \\
\text { todas as escolas da Rede Estadual do ensino regular e todos os alunos das séries/anos avaliados dos Ensinos } \\
\text { Fundamental e Médio. Grande parte dos alunos sentem muita dificuldade em realizar a prova externa, nesse } \\
\text { sentido vale ressaltar a importância de atividades diferenciadas, preparando-o para que o resultado seja positivo. }\end{array}$ \\
\hline OBJETIVOS & $\begin{array}{l}\text { Objetivo Geral: Revisão de diferentes gêneros textuais focando a avaliação Estadual SARESP } \\
\text { Objetivos Específicos: } \\
\text { - Ler e compreender, de forma autônoma, textos literários de diferentes gêneros e extensões, inclusive aqueles sem } \\
\text { ilustrações, estabelecendo preferências por gêneros, temas, autores } \\
\text { - Compreender e utilizar tecnologias digitais de informação e comunicação de forma crítica, significativa, } \\
\text { reflexiva e ética nas diversas práticas sociais (incluindo as escolares), para słøoomunicar por meio das diferentes } \\
\text { linguagens e mídias, produzir conhecimentos, resolver problemas e desenvolver projetos autorais e coletivos. } \\
\text { - Selecionar textos e livros para leitura integral, de acordo com objetivos, interesses e projetos pessoais (estudo, } \\
\text { formação pessoal, entretenimento, pesquisa, trabalho etc.). }\end{array}$ \\
\hline $\begin{array}{l}\text { PROCEDIMENTO } \\
\text { S }\end{array}$ & $\begin{array}{l}\text { Instrumentos Utilizados - Formulário a ser criado no Google para responder questões de tirinha com inferência; } \\
\text { Escrita de carta de leitor no site da Revista Ciência Hoje para Crianças; Post-it colado numa cartolina com o nome }\end{array}$ \\
\hline
\end{tabular}




\begin{tabular}{|c|c|}
\hline & $\begin{array}{l}\text { da história de contos de fadas a ser escolhida; Escolha de jornal, gibi ou livro com questionário sobre a escolha ao } \\
\text { fim; Criação de um Teatrinho de lendas com fantoches da escola; Leitura da instrução de um jogo; Envio de } \\
\text { mensagem no Whats App da sala de informática para a professora da sala; Mapa das estações para preenchimento } \\
\text { dos alunos e do professor. } \\
\text { Site Ciência Hoje: Carta de Leitor História de contos de fadas Formulário Google: tirinha Leitura das instruções } \\
\text { de jogos Teatro de lendas com fantoches da escola Escrita nome conto de fadas em post-it para colagem Escolha } \\
\text { de jornal, gibi, revista e/ou livro. } \\
\text { Como será a aula? Será trabalhado com } 3 \text { turmas dos } 3^{\text {o }} \text { Anos e } 2 \text { dos } 4^{o} \text { anos para avaliar os saberes e pensar em } \\
\text { um gráfico para análise dos assuntos a serem revistos para a avaliação Estadual SARESP; Os alunos terão } \\
\text { liberdade de escolha pois uma estação não dependerá da outra; Receberão um guia com todas as informaçôes sobre } \\
\text { cada estação, para ser preenchidas com o nome, série e marcação de quais estações ele passou e quanto tempo ficou } \\
\text { (de acordo com o cronômetro na lousa digital) em cada uma delas; Há várias estações porque o nível de } \\
\text { conhecimento dos alunos são diferentes e nem todos conseguem, por exemplo ler uma tirinha com inferência e } \\
\text { depois responder um questionário. O professor terá um mapa das estações que será preenchido quando os alunos } \\
\text { estiverem em cada estação, quem terminar tudo receberá um adesivo (mas não será falado), este será verificado } \\
\text { após a finalização da aula com o guia do aluno para confrontar os dados. Se a proposta fluir bem, vamos modificar } \\
\text { alguns itens para que os } 2^{o} \text { e } 3^{0} \text { anos também façam esta revisão, de acordo com as propostas da avaliação que será } \\
\text { feita no início de novembro. }\end{array}$ \\
\hline AVALI & A participação e o resultado das atividades realizadas pelos alunos. 761 \\
\hline RECURSOS & $\begin{array}{l}\text { RECURSOS MATERIAIS: Fantoches de folclore, computadores com o formulário do Google, histórias de contos } \\
\text { de fadas e com o site da Revista Ciência Hoje para Crianças, jornal, revista, gibi e livros, jogos com folheto de } \\
\text { instruções, celular com Whats App, cartolina, post-it, lápis, borracha e papel, lousa digital com cronômetro. } \\
\text { RECURSOS DIGITAIS (PARA O PLANO ADAPTADO): ENSINO HÍBRIDO - Rotação Individual com }\end{array}$ \\
\hline
\end{tabular}




\begin{tabular}{|c|l|}
\hline & ensino personalizado \\
\hline REFERÊNCIAS & $\begin{array}{l}\text { SÃO PAULO (Estado). Matrizes de Referência para a Avaliação. SARESP: documento básico. São Paulo: } \\
\text { Secretaria da Educação, 2009. }\end{array}$ \\
\hline
\end{tabular}




\section{PROCEDIMENTOS METODOLÓGICOS}

A metodologia utilizada é exploratória de pesquisa bibliográfica e documental, com abordagem qualitativa, isto é, periódicos científicos de material que é mais atual em livros, artigos, revistas, que abordem sobre o tema estudado. Como toda sociedade está amparada pelas Tecnologias de Informação, gradativamente elas estão ganhando espaço nas escolas e a perspectiva é que fiquem e colaborem para a construção de uma educação com ação integradora e colaborativa, propiciando uma grande desenvoltura no processo de ensino aprendizagem. Alicerçada por uma pesquisa bibliográfica, norteando por periódicos científicos de grande significância.

\section{RESULTADOS E DISCUSSÕES}

Diante do trabalho realizado, com as ideias dos autores e o plano de aula elaborado, observou-se que não basta mais ficar ensinando teorias e conceitos ultrapassados, e isso sugere em formar educadores dentro desta ideologia, que é a de enfrentar a dificuldade, refletir nos melhores recursos, investir em novas metodologias e aplicá-las no menor espaço de tempo, mas sem esquecer-se de conscientizar e conduzir os educandos de maneira que eles entendam as propostas tornando-os responsáveis pelo próprio desenvolvimento de suas capacidades.

Portanto, é necessário refletir e repensar a educação como um todo, desde os primeiros passos do educando em sala de aula até a sua formação superior e após ela, pois será esta a transformação tão sonhada e esperada por muitos, mas para que isso ocorra, é imprescindível o envolvimento dos educadores e estes precisam estar conscientes e ativos perante aos impactos desta decisão. As metodologias ativas por si só não são a solução do problema da educação, elas contribuem nesta mudança, mas com a participação e atuação dos educadores dentro desta proposta de transformação, novos degraus e expectativas serão adquiridos e uma nova geração de profissionais que irá transformar a sociedade em que vivemos e assim estarmos capazes para enfrentar novos níveis educacionais. 


\section{CONCLUSÃO}

O artigo teve como pressuposto básico, discutir e analisar como exercer uma docência na atualidade, de forma que o conhecimento dos educandos seja de fato consolidado. Além disso, revisitar alguns conceitos-chaves sobre a formação do educador numa perspectiva Freiriana, sobretudo propor um olhar mais atento, no que diz respeito às práticas pedagógicas, considerando o fato de estarmos na era digital. Buscando assim, utilizar-se de metodologias ativas a fim de que os alunos se tornam cada dia mais autônomos e independentes.

Atualmente, nota-se que a docência nos estabelece a cada dia, rever, transformar o ato de "ensinar", embora esse termo não se aplica muito bem ao nosso tempo, porque somos mediadores do conhecimento, não temos em tese essa capacidade de transferir conhecimento, podemos ajudar por meio de habilidades, além da paixão que exercemos na docência, indicar os caminhos.

O aluno de hoje nasceu na sociedade da tecnologia da informação e da comunicação. Já está preparado a interagir com este contexto, sobretudo, que está até desprovido da utilização destas metodologias no espaço escolar de maneira participativa, crítica, ética e construtiva. As metodologias ativas poderão ser de grande auxílio ao educador na mediação da construção do conhecimento se forem trabalhadas de maneira consciente, interagindo no cotidiano escolar com o processo de ensino e aprendizagem.

Sinaliza-se a importância do uso dos recursos na educação e para a educação. Como educadores devemos acompanhar as mudanças ocorridas em nossa sociedade, a fim analisá-las de forma crítica e construtiva, de modo a incorporar essa realidade social à realidade escolar com mais clareza e objetividade.

Contudo não basta somente saber, é preciso complementar o saber pelo saber fazer, desta forma, estimular os alunos para serem autodidatas e pessoas capazes de desenvolverem o hábito da autoaprendizagem, ou seja, aprender a aprender. 


\section{REFERÊNCIAS}

ABREU, Maria Célia; MASETTO, Marcos Tarciso. O professor universitário em aula. São Paulo: MG Editores Associados, 199o.

ANASTASIOU, Lea. G. C; ALVES, Leonir P. (Orgs). Estratégias de ensinagem. In: Processos de ensinagem na Universidade. Pressupostos para estratégias de trabalho em aula. 3. ed. Joinville: Univille, 2004.

ARROYO, Miguel. Fracasso-Sucesso: o peso da cultura escolar e do ordenamento da educação básica. In: ABRAMOWICS, A. E Moll, J. (orgs.) Para Além do Fracasso Escolar. Campinas, Ed. Papirus, 2000.

BERBEL, Neusi, A. N. As metodologias ativas e a promoção da autonomia de estudantes. Semina: Ciências Sociais e Humanas. Londrina, v. 32, n.I, 201 .

BONWELL, Charles C .; EISON, James A. Aprendizagem ativa: criando entusiasmo na Sala de aula. ASHE-ERIC Ensino Superior Relatórios.

I991.

BRASIL. Constituição (1988). Constituição da República Federativa do Brasil. Brasília, DF: Senado Federal: Centro Gráfico, 1988

. Lei de Diretrizes e Bases da Educação Nacional. LDB, № 9394/1996. Fixa as diretrizes e bases da educação nacional. Brasília: Ministério da Educação e Cultura, 1996.

FAXINA, Jonas. A influência que a relação afetiva entre professor e aluno exerce no processo. 2005, 72 f. Trabalho de conclusão de curso em Pedagogia. Faculdade de Ciências. Universidade Estadual Júlio de Mesquita Filho. Bauru, 2005.

FERACINE, Luiz. O professor como agente de mudança social. São Paulo: EPU, 1998.

FILATRO, Andrea. CAVALCANTI, Carolina Costa. Metodologias inov-ativas na educação presencial a distância e presencial. Saraiva Uni, 2018.

FREIRE, Paulo. Pedagogia da autonomia: Saberes necessários à prática educativa. São Paulo: Paz e Terra, 1996.

GADOTTI M. Perspectivas atuais da educação. Porto Alegre ed. artes médicas 2000.

GUILLOT, Gérard. O resgate da autoridade em educação. Porto Alegre: Artmed, 2008.

LIBÂNEO, José Carlos. Educação Escolar: políticas, estrutura e organização. São Paulo: Cortez, 2005. 
MARTINIC, S. Tempo e aprendizagem escolar: a experiência da extensão do dia letivo no Chile. In: Revista Brasileira de Educação. V.20, n. 6I, p. 479-499, abr-jun. 2015.

MORA, E. Neuroeducação: você só pode aprender que que se ama. Madrid: Alianza Editorial, 2013.

MORAN, José. Metodologias Ativas para uma Educação Inovadora: Abordagem TeóricoPrática. Penso Editora. Porto Alegre. 2018.

PAIVA, M. R. F. et al. Metodologias ativas de ensino-aprendizagem: revisão integrativa. Sanare: Revista de Políticas Públicas. Sobral, v. I5 n. 2, p. 145-153, jun./dez., 2016.

PEREIRA, Rodrigo. Método Ativo: Técnicas de Problematização da Realidade aplicada à Educação Básica e ao Ensino Superior. In: VI Colóquio Internacional Educação e Contemporaneidade. 6, 2012, São Cristóvão-SE. Anais... São Cristóvão: 2012.

PIMENTA, Selma. Garrido. (Org.) Professor Reflexivo no Brasil. 3 ed. São Paulo: Cortez, 2005 .

RODRIGUES, M. L. V. Aprendizado centrado em problemas. Medicina, Ribeirão Preto, v. 29, p. 396-402, out./dez. 2016.

SANTOS, Edméa. Educação online para além da ead: um fenômeno da cibercultura. In: CONGRESSO INTERNACIONAL GALEGO-PORTUGUÊS DE PSICOPEDAGOGIA, 2009. Braga. Trabalhos Completos... Braga: Universidade do Minho, 2009.

SAVIANI, Dermeval. História das ideias pedagógicas no Brasil - Campinas SP: Autores associados, 2007.

SOUZA, Juliana Bezerra de. AMARAL, C. L. C.; LEITE, SCHIMIGUEL, Juliano. Metodologia ativa na educação. São Paulo: Pimenta Cultural, 2006.

TEIXEIRA, Anísio Spíndola. Educação é um direito. 4. Ed. Rio de Janeiro: Editora UFRJ, 2009.

ZABALA, Antoni. A prática educativa: como ensinar. trad. Ernani F. da F. Rosa. Porto Alegre: ArtMed, 1998. 